
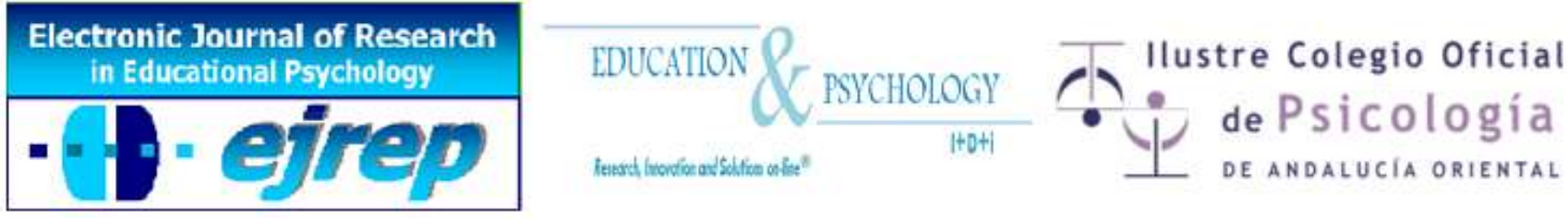

\title{
Towards the Solution of Abysmal Performance in Mathematics in Junior High Schools: Comparing the Pedagogical Potential of two Designed Interventions
}

\section{Frederick Kwaku Sarfo ${ }^{1}$, Grace Eshun ${ }^{2}$, Jan Elen ${ }^{3}$, Kobina Impraim Adentwi ${ }^{4}$}

${ }^{1}$ Department of Educational Leadership, University of Education, Winneba, Kumasi campus, Kumasi, Ghana

${ }^{2}$ Department of Mathematics, Baidoo Bonsoe Senior High School, Agona Ahanta, Ghana

${ }^{3}$ Center for Instructional Psychology and Technology, Catholic University of Leuven, Leuven, Belgium

${ }^{4}$ Department of Interdiscilinary Studies, University of Education, Winneba, Kumasi Campus, Kumasi, Ghana

\section{Ghana/Belgium}

Correspondence: Frederick Kwaku Sarfo. Department of Educational Leadership, University of Education, Winneba, Kumasi Campus, P.O.Box 1277, Kumasi Ashanti, Ghana. E-mail: sarfofredk2001@yahoo.com 


\begin{abstract}
Introduction. In this study, the effectiveness of two different interventions was investigated. The effects of a concrete abstract intervention and a regular method of teaching intervention were compared. Both interventions were designed in line with the specifications of classical principles of instructional design for learning mathematics in the traditional classroom of junior high school (JHS) in Ghana. The purpose was to contribute to the solution of abysmal performance of mathematics in the JHS.
\end{abstract}

Method. Eighty students randomly selected from JHS, were randomly assigned to the two treatments. The content for the treatments were selected from the JHS syllabus. A teacher was trained to implement the treatments. The main study, consisting of six sessions, was conducted in a regular classroom of the school. Descriptive statistics, paired-samples $t$ test, and $t$ independent test were used to analyze the data.

Results. Generally, the general performance of students in both groups improved significantly after they had experienced the designed treatments. Comparatively, $t$ independent test revealed that the designed concrete representational abstract intervention (DCRAI) is more effective for improving students' general performance in geometry and algebra than the designed regular method of teaching intervention (DRMTI).

Discussion and conclusion. The results of the study imply that instructional design principles are relevant, effective and needed in the design of classroom teaching, to address the poor performance in mathematics in JHSs (in Ghana).

Keywords: Representational abstract, instructional intervention, regular method of teaching, mathematics, junior high school. 


\section{Hacia la Mejora del Rendimiento Matemático Pésimo en el Primer Ciclo de Enseñanza Secundaria: una Comparación del Potencial Pedagógico de dos Intervenciones.}

\section{Resumen}

Introducción. En esta investigación se investigó la eficacia de dos intervenciones diferentes. Se compararon los efectos de una intervención concreta y abstracta con un método regular de intervención docente. Ambas intervenciones fueron diseñadas de acuerdo con las especificaciones de los principios clásicos de diseño de instrucción para el aprendizaje de las matemáticas en el aula tradicional de la Escuela Secundaria (ES) en Ghana. El objetivo era contribuir a la solución de las diferencias abismal de desempeño en las matemáticas en este nivel.

Método. Ochenta estudiantes seleccionados al azar de ES, fueron asignados al azar a los dos tratamientos. El contenido de los tratamientos fueron seleccionados a partir del programa de estudios. Un profesor fue entrenado para aplicar los tratamientos. El estudio principal, que consta de seis sesiones, fue la conducta de opinión en un salón de clases regular de la escuela. Se utilize estadística descriptive para muestras relacionadas, con una prueba t y t-dependiente para el análisis de datos.

Resultados. En general, el rendimiento de los estudiantes de ambos grupos mejoraron significativamente después de que hubieran experimentado los tratamientos diseñados. Comparativamente, la prueba $t$ independiente reveló que la consistente intervención abstracta, a través de un diseño representacional (DCRAI), tuvo más eficacia para mejorar el rendimiento general de los estudiantes en geometría y álgebra que el método regular de intervención docente (DRMTI).

Discusión y conclusión. Los resultados de la investigación evidencian que los principios de diseño de instrucción son pertinentes, eficaces y necesarios en el diseño de la enseñanza en el aula, para hacer frente a los malos resultados en matemáticas en ES en Ghana.

Palabras clave: Representación asbtracta, diseño instruccional, método regular de la intervención docente, matemáticas, escuela secundaria. 


\section{Introduction}

Mathematics literacy is the ability to apply skills and concepts, reason through, communicate about, and solve mathematical problems (NCTM, 1989). It helps students to play mathematically, think mathematically, talk mathematically, and work or solve problems mathematically. As indicated by the National Mathematics Advisory Panel (2008), mathematics is the invisible culture of our age; it manifests in our lives in many ways: practical, civic, professional, recreational, and cultural. More especially, in this technological era, number sense, algebra and problem solving skills in mathematics are attracting more attention. This is because advancement in technology, such as calculators, computers, software programs, enhances both the opportunities for, as well as the demands of, advanced levels of proficiency in mathematics (Little, 2010). Due to its importance in our lives, policy makers, educators, employers, and parents worldwide are increasingly becoming interested in mathematics curricula and students' performance in mathematics at all levels of education.

In Ghana, the mathematics curriculum (syllabus) of basic education was designed based on the recognition that mathematics is not only a collection of concepts and skills to be mastered but also involves processes that will help the individual to develop his ability to explore, conjecture, solve problems and reason logically (Ministry of Education, 2007). Due to its importance, mathematics is one of the core subjects at the basic education level. Despite the critical role mathematics plays in intellectual and social development of the students and despite the lavish attention paid to the study of mathematics in Ghana, students at the basic level do not perform well in mathematics examinations.

The abysmal performance in mathematics of basic school students (Grade 8 - in Ghana also called Junior Secondary School $\{$ JSS2 $\}$ or Junior High School $\{$ JHS2 $\}$ ) is evident in the results of the Trends in International Mathematics and Science Studies (TIMSS) 2003 and 2007 (Anamuah-Mensah \&Mmereku, 2005; Appiah, 2010) as well as in the Basic Education Certificate Examination (BECE) (West Africa Examination Council [WAEC], 2008, 2009, 2010, 2011). TIMSS is a series of studies undertaken once every four years by the International Association for the Evaluation of Educational Achievement (IEA) to examine students' achievement in science and mathematics (Anamuah-Mensah \&Mmereku, 2005). Ghana participated in TIMSS 2003 and 2007 to compare its educational potential with other countries that participated (Appiah, 2010). According to Anamuah-Mensah and Mmereku(2005), the 
importance of mathematics and science in today's technological society provides a context for the comparison.

TIMSS assessment is organized around two dimensions; these are the content dimension and the cognitive dimension. The content domain includes number, algebra, measurement, geometry and data. The cognitive domains involve knowing facts and procedures; using concepts; solving routine problems, and reasoning (Anamuah-Mensah \&Mmereku, 2005). TIMSS uses the international average in reporting students' achievement in science and mathematics as well as the international benchmarks to describe achievement at those benchmarks in relation to students' performance on the test. The benchmarks which represent the range of performance shown by students internationally are: a) Advanced international benchmark 625; b) High international benchmark - 550; c) Intermediate international benchmark 475; and d) Low international benchmark 400 (Anamuah-Mensah \&Mmereku, 2005; Appiah, 2010). The analyses of the results of TIMSS 2003 and 2007 indicate that the performance of Ghanaians JHS 2 pupils in mathematics was among the lowest in Africa and the World. In 2003 , out of 46 countries that participated, Ghana was second from the bottom of the results table with mean mathematics score of 276 far below the international mean score of 467 (Anamuah-Mensah\&Mmereku, 2005), and also far below the low international benchmark of 400. In 2007, the mean mathematics score of Ghanaian JHS2 pupils was 316, far below the international mean score of 500 (Appiah, 2010), and also far below the Low international benchmark score of 400 .

Poor performance in mathematics at the basic level of education in Ghana has attracted a lot of attention of the government, mathematics educators, educational researchers, instructional designers, parents, and employers and calls for immediate solutions. AsabereAmeyaw and Mmereku (2009) indicate that contextual factors such as limited use of technology (i.e. computers and calculators) might account for the poor performance in mathematics. And they thus proposed that the integration of ICT into teaching and learning (of mathematics) at the Basic education could salvage the situation. Van der Linde (2005) contends that the poor performance of Ghanaian students as well as others from African countries could be attributed to other factors including issues of poverty. Anamuah-Mensah and Mmereku (2005) argued that the Ghanaian mathematics curriculum does not meet requirements that are currently valued globally in school mathematics. According to Owu-Ewie (2012), language performance and that of science and mathematics of JHS students at the basic level in Ghana are 
positively and significantly correlated. And for this reason, according to Owu-Ewie (2012), one of the factors that accounts for poor performance in mathematics and science is language. Others (e.g., Fredia-Kwarteng, 2005; Appiah 2010) indicate that such poor performance, more especially in TIMSS 2003 and 2007, could be attributed to differences in pedagogical orientation. Fredia-Kwarteng (2005) explains that, in Ghana, mathematics teaching at JSS2 is characterized by transmission and command models. Pupils are not encouraged to pose questions or engage in hands-on activities and problem-solving activities in order to attain both conceptual and procedural understanding of what they are taught (Fredia-Kwarteng, 2005; Appiah, 2010). Most of the JHS pupils in Ghana have inadequate conceptual understanding of mathematics content taught at the basic level (Baffoe\&Mmereku, 2010). In a research study, Baffoe and Mmereku (2010) identified that the performance in geometry of JHS students in Ghana, before entering senior high school, is lower than most students (at this age) in other countries. In addition, the students lack appropriate cognitive/learning strategies. What might have given rise to these learning problems, to some great extent, is that teachers often use inappropriate instructional strategies in the classrooms (Baffoe\&Mmereku, 2010).Based on their research findings, Baffoe and Mmereku (2010) indicated that the teaching and learning of geometry at the basic level should involve more hands-on activities that actively engage the students. For instance, Appiah (2010) asserts that Ghana can learn from some of the countries, such as Singapore, which performed very well in 2003 and 2007 TIMSS. The Singapore National Curriculum emphasizes problem solving skills through meaningful communication (or oral work), group discussion and presentation, investigative work and mathematical thinking (San, 2000).

There is evidence from the literature on instructional design (e.g., Clark, 2001; Sarfo $\&$ Elen, 2007, 2008) that good design of intervention is the most effective means of promoting successful learning. Instructional design models provide efficient and systematic guidelines for designing effective instruction (Seel, 1997; Elen, 1995; Gagne, 1985).This research study argues that effective design of intervention "concrete representational abstract intervention" or "regular method of teaching intervention", based on classical principles of instructional design could improve the current situation of learning mathematics in JHSs (in Ghana).

\section{Effective design of instruction}

Clark (2001) specifies that the necessary condition or active ingredient of treatment which is sufficient to cause learning from instruction or teaching is best characterized as in- 
structional method, not media or ICT. It is the instructional method that activates, compensates or supplants the cognitive processes necessary for learning (Clark, 2001). Clark defines instructional method as the provision of cognitive processes or strategies that are necessary for learning but which students cannot provide for themselves. All methods (e.g., examples, demonstration, feedback, questions) required for learning can be delivered by a diversity of media (both low cost and high cost). Smaldino, Lowther, and Russell (2008) emphasize that the 'magic' in computer technology, if it existed, all lies in the instructional design of the method or software, and not in the hardware. The results of the study conducted by Sarfo and Elen $(2007,2008)$ to test the effects of powerful learning environments with and without computer indicated that it is effective design of the instruction and not the technology that matters. In a study of the effectiveness of reading and mathematics with and without computer on standardized test scores, Dynarki et al. (2007) found no significant improvement in scores between treatments. The above scientific evidence, and many others, in the literature attest to the fact that the design of an intervention is the fundamental building block and therefore the most effective means for promoting successful learning. Achieving quality teaching, at the basic education level, towards successful learning of mathematics especially depends on the systematic design of the instruction. Instructional design models are regularly used to develop specific aspects of instruction (Seel, 1997). An instructional design model (ID model) describes or shows the main elements of an instructive program, and most often lists a number of variables to be considered in designing efficient and effective instruction. Gagne (1985) and Gagne and Briggs (1979) developed a series of events, for effective teaching. Gagne's nine events of instruction is considered as a classical instructional design model for designing efficient and effective instruction in the classroom. It provides efficient and effective support for designing and implementing effective teaching intervention. The nine events of instruction support the internal learning process and focus on the achievement of outcome or behavior of instruction. The events include: 1) gaining learners' attention, 2) informing learners about the objective, 3) stimulating the recall of essential prerequisite knowledge, 4) providing stimulus material, 5)providing learning guidance and support, 6) eliciting students' performance, 7) providing feedback, 8) assessing students' performance, and 9) enhancing retention and transfer. Gagne explicitly prescribes various techniques that are used to facilitate the execution of each event during teaching. 


\section{Concrete representational abstract intervention}

Research has shown that concrete representational abstract (CRA) intervention is an effective instructional intervention for teaching mathematical concepts, procedures; while also facilitating students' problem solving in mathematics (Witzel, 2005; Witzel, Riccomini\& Schneider, 2008; Strickland \& Maccini, 2010). Teaching mathematics using manipulative materials has a long history. In the $19^{\text {th }}$ century, Pestalozzi advocated their use, and manipulative materials were included in the activity curriculum of the 1930s. The mid 1960s was another period of emphasis on using concrete objects and pictorial/drawings representations in mathematics (Sowell, 1989). In the late 1980s, researchers (e.g., Peterson, Mercer, \& O’Shea, 1988) compared, in a number of instructional settings, outcomes of mathematics instruction with a concrete - representational - abstract sequence, to outcomes of mathematics instruction with an abstract only traditional method of teaching. The results indicate that CRA can help students learn mathematics better than the traditional method of teaching. The CRA instructional intervention consists of three levels (Witzel et al. 2008; Strickland \&Maccini, 2010):

a. $\mathrm{C}=$ Concrete: learning through concrete devices or hands-on instruction by using actual physical manipulative objects, such as milk tins, cut cardboard, cubes, beads, algebra tiles.

b. $\mathrm{R}=$ Representational: learning through the use of pictures or drawings to represent (or as a representation of) the previously used manipulative objects during concrete instruction.

c. $\mathrm{A}=$ Abstract: learning through abstract notations such as Arabic numbers, symbols, and variables: This level involves helping students to solve numeric problems (e.g., 2x $+5=8$ ) without manipulative devices.

The three stages of the CRA instructional intervention are interconnected; should be followed sequentially, and should not be treated as isolated activities during instruction (Witzel et al. 2008). The students' successful use of the three stages during teaching is essential for successful learning of the skill targeted and understanding the related concepts (Witzel et al., 2008). Thus each stage builds upon the previous one to enhance overall conceptual understanding and procedural accuracy and fluency. Evidence gleaned from the literature (e.g., Kroesbergen\& Van Luit, 2003; Miller, Butler, \& Lee, 1998) reveals that when manipulative devices and pictorial representations are used to teach mathematics to students with learning 
difficulties, learning becomes successful. The sequential use of manipulative devices and pictorial representations helps students to develop conceptual knowledge and promotes students' problem solving skills in mathematics (Witzelet al., 2008; Kroesbergen \& Van Luit, 2003). This is reflected in the findings of Delvin (2000) that for students to understand abstract concepts more easily and solve problems in mathematics, it is important for them to learn precursor concepts in a concrete manner first. One way to simplify students' understanding of abstract concepts is to transform such complex concepts into concrete manipulations and pictorial representations (Witzel, 2003).

The pedagogical effectiveness of CRA instructional approach in the teaching of mathematics has been empirically tested in several instructional settings such as middle/high schools, secondary schools, and primary schools to teach addition, subtraction, algebra, geometry to students with or without learning difficulties (Witzel et al.,2008; Cass, Cates, Smith, \& Jackson, 2003).

In a research study, Witzel, Mercer, and Miller (2003) worked with 10 general education teachers and over 350 sixth and seventh grade middle school students in inclusive mathematics education classes. The teachers delivered 19 fifty-minute lessons on algebra instruction. Classes were assigned to either the treatment or the comparison group. The instructional content and pacing were identical across conditions. The only difference was that the comparison group's lessons were conducted at the abstract level, whilst the treatment group provided instruction first at the concrete level, then at the representational level before proceeding to the abstract level. The analysis of data drawn from 34 matched pairs of students from the control and treatment groups indicated that students who received CRA instruction achieved posttest scores that were significantly higher than those of their matched peers in the comparison group. In a subsequent analysis of the full set of data, Witzel (2005) examined pretest, posttest, and follow-up test scores of 231 students enrolled in inclusive middle school Algebra 1 courses. Witzel found that students in the CRA-intervention condition outperformed peers on both the posttest and the follow up test than students in a comparison condition in which all the instruction was provided at the abstract, or symbolic level.

However, in spite of the research evidence to urge teachers to implement CRA intervention in the classroom, there is dearth of appropriate guidelines or methodological references to explicitly support how to use or adapt CRA intervention appropriately to teach math- 
ematics in secondary and basic schools (Witzel et al. 2008). According to Witzer et al. (2008), the lack of methodological guidelines or instructional design support for teachers impede the effective design and use of CRA interventions in the traditional classroom to promote successful learning of mathematics. Towards this limitation, in the present study, it is proposed that nine events of instruction provide efficient and effective systematic support and guidelines for designing CRA intervention to teach mathematics in the classroom.

\section{Regular method of teaching intervention}

Butler, Miller, Crehen, Babbit, and Pierce (2003) indicate that there are a number of inherent challenges regarding the proper use of concrete manipulative devices of CRA intervention in the traditional classroom. Among the challenges are: managing the dissemination and collection of the concrete objects, providing adequate work space, ensuring that all students have an appropriate number of concrete objects, monitoring accuracy of students' performance (Butler et al.2003). Considered these challenges and the fact that CRA intervention seems to be more complex for teachers to implement effectively in the traditional classroom (Witzer, et al., 2008), there is a need to identify an alternative intervention that might be as effective as a CRA intervention. The implementation of the suggested alternative intervention in the traditional classroom should not be more challenging and complex as DCRAI but should be as effective. Evidence gathered from the literature (e.g., Sarfo \& Elen, 2007, 2008) shows that when the regular method of teaching is designed based on the classical principles of instructional design it yields better learning of technical subject. The regular method of teaching is referred to as classroom teaching that focuses on abstract concepts and some few illustrations and drawings on the blackboard. The regular method of teaching follows a regular structure: activating prior knowledge, presenting relevant information, exercises made by the students and continuous feedback by the teacher. It is, again, argued in this study that effective design of regular method of teaching intervention (RMTI) based on the principles of instructional design might be as effective as DCRAI in solving the problem of abysmal performance in mathematics

\section{Aim of the study}

In Ghana, the curriculum of JHS covers 4 core subjects and 5 elective subjects. The 4 core subjects include mathematics, English, Social Studies, and Integrated Science. Some of the content treated in mathematics are: linear equation and inequalities, set, vectors, probability, trigonometry, statistics, business- math, construction, algebra and geometry. More specif- 
ically, this study is experimentally designed to compare the pedagogical potential of DCRAI and DRMTI for improving students in JHS performance in geometry and algebra (to understand geometrical and algebraic concepts and solve problems in geometry and algebra) in the traditional classroom (in Ghana). In other words, the study is aimed at experimentally investigating the effectiveness of CRA intervention and traditional method of teaching intervention designed in line with classical principles of instructional design for teaching and learning of mathematics in the traditional classroom of JHS. The intention is to contribute to the solution of abysmal performance of mathematics in JHSs (in Ghana) from instructional design perspective.

\section{Method}

\section{Participants}

The participants for the study were first year junior high school students selected from one of the junior high schools in the Ahanta-West District of the Western Region, Ghana. The whole class had an enrolment of 187 students made up of 86 girls and 91 boys. The researcher carried out the study with 80 students (40 males and 40 females; mean age $=14$, SD = 1.2). The participants were randomly divided into 2 groups.

\section{Research materials}

The terminal objective was selected from JHS first year mathematics syllabus in Ghana. Research materials included 1) materials and teacher guidelines for the two treatments (DRMTI and DCRAI) and 2) assessment tasks for the pre-test and post-test.

Both treatments were designed to support the learners to achieve the same terminal objective of this study. The terminal objective consisted of 4 instructional tasks. Each instructional task consists of 3 specific instructional objectives. Both treatments were designed based on the classical principles of instructional design (Gagne 1985; Gagne \& Briggs 1979; Leshin, Pollock, \& Reigeluth; 1992). The components common to each lesson for both groups are: gaining learners attention, activation, informing learners about the objectives, presenting stimulus materials (description of activity, presenting materials in small sets, model procedures, provide examples and non examples, etc), guided practice, providing feedback, assessing learners' performance and independent practice. The content for the two treatments is 
also identical and related to the terminal objective. The content included: polygons, angles, parallel lines, triangles, area and perimeter of triangles and quadrilaterals, and algebraic expression selected from the syllabus. The information on the topics was selected from the required textbook and some were provided by the subject matter teacher who taught all the lessons. Each treatment consisted of four lessons, and the instructional time for each lesson was 60 minutes (this is normal time for 2 teaching periods in JHS in Ghana). Each lesson covered one instructional task under the terminal objective. The teaching of the two groups took place in the same classroom setting (classroom where the students have been having their regular classes). However, there were some variations in the two treatments in terms of the strategies and delivery.

For the DRMTI treatment group, the teacher introduced the lesson, modeled a new procedure, guided students to use procedures, and then assisted students working independently. All activities focused on abstract concepts. The teacher used explanations, demonstrations, illustrations on the blackboard, examples and non examples to help learners understand and apply abstract concepts such as triangle, rectangle, $\mathrm{LxB}, 4 \mathrm{x}=6,20^{\circ}$ etc. In the DCRAI treatment group, the teacher introduced the lesson. Then at each stage of concrete, representational, and abstract, the teacher modeled a new procedure, guided students to use procedures, and then assisted students working independently. All activities focused on concrete, representational and abstract concepts. The teacher used explanations, demonstrations, examples and non examples and illustrations to help learners to understand each of the stages. For the lessons related to conceptual understanding of geometry, the teacher used cutting cardboard, ropes, wall clock as concrete objects. Then she used pictures and drawings on the cardboard and the chalkboard for the representational aspects, finally she wrote the equivalent symbols and numbers on the blackboard. For the lessons related to the conceptual understanding and application of algebraic expression, the teacher used pieces of chalk, beads, and sticks as concrete objects, drawings on the blackboard for the representational aspects, and then finally wrote symbols and numbers on the blackboard for abstract components. For lessons related to the perimeter and circumference of rectangles, circles, etc, the teacher used cutting cardboard and ropes to represent the concrete objects, drawings and pictures on the blackboard and cardboard to represent the representational aspects, and then finally wrote the symbols and numbers of the blackboard for the abstract aspects. 
The assessment tasks consisted of 20 questions: 10 pre-test assessment questions ( 5 understanding questions and 5 application questions) and, ten post-test assessment questions (5 understanding questions and 5 application questions). All questions were constructed based on the topics selected from the syllabus towards the achievement of the terminal objective.

The understanding test items were designed to assess if learners developed understanding in the geometrical and algebraic concepts of the objective. The application test items were also designed to assess if learners developed problem solving skills in geometry and algebra content taught. That is, if they can apply algebra to solve problems in geometry. The pre- and posttest were parallel tests: they had the same format and covered the same content in geometry and algebra in mathematics. For instance pretest item number 3 " $A$ small garden $/ A B C E /$ of length 3 meters has a perimeter of $22 \mathrm{~m}$. If a child stands at/D/ (the middle of the length $/ E C /)$ and walks toward the diagonal /A/to make a triangle AED. How many triangles will fix the garden /ABCE/? which measured students' problem solving skills had the same level of difficulty and content as posttest item number 7 "A piece of land of length $25 \mathrm{~cm}$ has a perimeter of $80 \mathrm{~cm}$. A canopy of length $5 \mathrm{~cm}$ and breath $3 \mathrm{~cm}$ is fixed on the land. How many of such canopies can fill the size of the land?" .Then pretest item number 7 "find the value of degrees of angles marked within letters $q, m, n$ " which measured students' conceptual understanding had the same difficulty level and content as posttest number 5 " find the value of degrees in each of the following: 1) three quarters of a turn and 2) two fifths of a turn"..A detailed marking scheme was prepared for accurate, systematic and objective marking of the tests. Both the pre and post tests and the marking scheme were reviewed by the senior researcher and a subject matter expert before being administered.

\section{Procedure}

One mathematics teacher was trained to deliver the two designed treatments as it was intended to ensure treatment fidelity in the normal classroom context (Krathwohl, 1993). A pilot study was conducted to improve the study materials and also to enable the researcher to control the factors that could other wise confound the experiment. After the pilot study the teacher was briefly retrained and respectfully instructed to teach the treatments in accordance with how she was trained. The senior researcher monitored the implementation of the treatments. 
The first day of the experiment was used to administer the pre-test. All 80 students sat in one particular classroom (at the church premise) that the school uses for terminal examinations. After the students had taken the pre-test, they were randomly divided into 2 groups which were randomly assigned to the two treatments. The administration of the pre-test took 60 minutes. The teacher used 4 days to teach the two treatments. Each day, she taught one lesson (60 minutes) of each treatment. The first day she taught the treatment for the DRMTI group first, then after 2 hours rest, she would work with the DCRAI group. In the second day she taught the DCRAI group first followed by the DRMTI. The two groups didn't know which treatment they belonged to; in fact, they had no idea only that they were asked to cooperate since the exercise would help them. The teaching for the 2 groups took place in their regular classroom. The teacher presented the 2 treatments systematically as designed. The researchers administered the posttest during the sixth day in the same room the pretest was administered; and the administration took 60 minutes as the pretest. The pre-and post tests were all put together, including the marking scheme, and submitted to a naïve SME for blind marking. The mathematics teacher remarked the tests and the differences were discussed with the main researchers.

\section{Overall design and data analysis}

Considering the purpose of the study, the research design was a pre-test post-test true experimental design (Campbell and Stanley, 1963; Krathwohl, 1993). A total of 80 students were randomly selected from 187 JHS 1 students from one of the JHSs in Ghana. The BECE results released by West Africa Examination Council (WAEC, 2008, 2009, 2010, 2011) of this particular school indicate that they perform very poorly in mathematics as compared to the other core subjects (see Table 1). A pretest was administered to measure their prior knowledge of the terminal objective "using algebraic expression to solve problems in geometry". Next, the students were randomly exposed to two different treatments. The treatments were 1) the DRMTI (40 students) and 2) DCRAI (40 students). A posttest was administered, after the two groups experienced the treatments, to measure the achievement of the terminal objective. The pre and posttest assessment tasks were adapted from the BECE (WAEC) examination questions; and they were based on the topics related to the terminal objective selected from the JHS mathematics syllabus. In order to recheck the quality of the assessment tasks, reliability tests were performed. The reliability co-efficient for the pre and post-test assessment tasks were 0.73 and 0.76 respectively. Descriptive statistics, paired-samples $t$ test and $t$ independent (between groups design) test were performed to analyze the data. 
Table 1. BECE results from WAEC (2008-2011) for the selected school

\begin{tabular}{|c|c|c|c|c|}
\hline $\begin{array}{l}\text { Subject } \\
\text { Year }\end{array}$ & Mathematics & $\begin{array}{l}\text { Social } \\
\text { Studies }\end{array}$ & IntegratedScience & $\begin{array}{l}\text { English Lan- } \\
\text { guage }\end{array}$ \\
\hline \multicolumn{5}{|c|}{ Percentage Passes } \\
\hline 2008 & 50.00 & 94.88 & 85.00 & 88.36 \\
\hline 2009 & 45.85 & 67.00 & 100.00 & 100.00 \\
\hline 2010 & 35.05 & 98.18 & 100.00 & 71.82 \\
\hline 2011 & 34.09 & 79.00 & 79.00 & 84.88 \\
\hline
\end{tabular}

\section{Results}

A $t$ independent test on the pre-test revealed no significant difference between the two groups of students. Table 2 shows the overview of the mean scores.

\section{Students' performance on the pre-test and the post-test}

Paired-samples $t$ test revealed statistically significant difference between students' performance on the pre-test and post-test of 1) the DTMTI condition $(t(39)=6.80, p<001)$ and 2) the DCRAI condition $(t(39)=14.97, p<001)$. The performance of the two groups on the post-test was better than the performance of the two groups on the pre-test. Table 2 depicts the mean scores for the pre-test and the post-test.

\section{Effect of the two treatments}

Generally, $t$ independent test performed on posttest revealed a significant difference between DRMTI and DCRAI $(t(78)=2.43, p<0.05$, Cohen $d=0.54)$. Students in DCRAI condition generally performed better $(\mathrm{M}=48.48)$ than the students in DRMTI condition (39.50) on the post-test with a medium size effect. Table 2 shows the overview of the mean scores of the post- test. 
Table 2. Overview of mean scores for the pretest and the posttest

\begin{tabular}{lllll}
\hline & Condition & $\mathrm{N}$ & Mean & SD \\
\hline Pretest & DTMT & 40 & 31.72 & 18.93 \\
& DCRAI & 40 & 30.82 & 18.40 \\
& Total & 80 & 31.29 & 18.50 \\
\hline Posttest & DTMT & 40 & 39.05 & 19.00 \\
& DCRAI & 40 & 48.48 & 16.12 \\
& Total & 80 & 43.76 & 18.40 \\
\hline
\end{tabular}

\section{Discussion and Conclusions}

The purpose of this experimental study was to compare the effectiveness of DRMTI and DCRAI on the learning of algebra and geometry in JHSs. The study was conducted in an ecological setting. The content and the objective were selected from the syllabus. The subjects were randomly selected and assigned to the treatments.

Generally, paired-samples $t$ test showed that the general performance of students in both groups improved significantly after they had experienced the four lessons in each treatment. The result revealed that both interventions are effective for teaching students to use algebraic expression to solve problems in geometry. Thus the two interventions promote the development of conceptual understanding of geometry and algebra; and also seem to improve students' problem solving skills in geometry and algebra. This implies that both designed interventions could address poor performance in mathematics in JHS (in Ghana). The traditional method of teaching used in both junior high and senior high schools in Ghana does not facilitate teaching (Anamuah-Mensah, 1998) and learning of mathematics (Appiah, 2010; Baffoe \& Mmereku, 2010). In this research study, the DRMTI differs from the traditional method of teaching used in JHS in Ghana. This is because the DRMTI was systematically designed based on classical instructional design principles. Even though the DRMTI was not as effective as DCRAI on the development of conceptual understanding and problem solving skills in geometry and algebra mathematics, it resulted in learning geometry and algebra in the traditional classroom. This finding is consistent with the research findings of Sarfo and Elen $(2007,2008)$ that if the teaching methods used in secondary technical schools are designed in line with instructional design principles, better learning is the outcome. 
Comparatively, $t$ independent test revealed that DCRAI is more effective for improving students' general performance in geometry and algebra than the DRMTI. This finding indicates that DCRAI is more effective in solving the problem of abysmal performance in mathematics in JHS. The result that DCRAI is more effective for teaching geometry and algebra is consistent with the findings (e.g. Witzel et al. 2003; Witzel, 2005; Witzel et al. 2008; Stricckland \& Maccini, 2010) that CRA instructional approach is effective for teaching mathematics at the middle, high, and secondary schools. However, Witzelet al. (2008) and Butler et al. (2003) indicate that CRA instructional approach is not a simple process to apply by teachers to mathematics content. The lack of appropriate and necessary guidance, at least, partially impedes the effective design and use of CRA instructional approach by teachers (Witzel, 2008); and its effective implementation in the classroom involves a lot of challenges (Butler et al., 2003). In this study, the successful implementation of DCRAI in learning algebra and geometry in the traditional classroom might be partly due to the systematic amalgamation of classical instructional design principles and CRA intervention. The systematic support and guidelines, based on the principles of instructional design, reduced the complexities and challenges related to the use of CRA intervention and made the implementation of the DCRAI more efficient and effective with fairly substantial effect size (indicating that it is important in practical terms). In addition, what might make DCRAI more effective in this study is in line with the explanation that the use of concrete manipulative and hands-on materials encourages the development of conceptual understanding and procedural fluency for students (Witzer, 2005, Witzer et al. 2008; Baffoe \& Mmereku 2010) . And this facilitates the development of problem solving skills (Witzer et al., 2008)

The findings of the study have raised very significant issues, related to teaching and learning of mathematics at the basic education level (in Ghana), for researchers, practitioners and policy makers. The present study has provided empirical evidence that the two designed interventions; more especially the DCRAI, can rather easily be implemented in the traditional classroom of JHS; and they are an appropriate and effective solution to weak performance in mathematics at the basic education (in Ghana). The materials needed to facilitate the teaching of the two designed interventions can be obtained at low cost by the school; can be designed by teachers; and can also be designed by students. This implies that, the present study has contributed to effective inexpensive teaching strategies for addressing the problem of abysmal performance in mathematics in JHSs (in Ghana). Some of the research studies(e.g., Butleret 
al., 2003) conducted to validate the effectiveness of CRA approach on learning of mathematics were conducted in resource rooms rather than the traditional classroom. The present study was conducted in an ecological setting. This implies that the study has contributed to revealing the effectiveness of CRA interventions also in traditional classrooms. To support the research base of DCRA and DTMT for effective teaching of mathematics in ecological setting and as solution to abysmal performance in mathematics, further research is suggested to use DRMTI and DCRAI interventions to teach different mathematics content in the syllabus of JHS. The suggested studies may add two different conditions "undesigned regular method of teaching treatment" and "undesigned CRA treatment" and use more participants from different JHSs (in Ghana).

Furthermore, the study has contributed to the methodological references for effective design and use of CRA approach in normal classroom setting. The study successfully combined the validated instructional design principles with CRA intervention. This implies that instructional design principles are relevant, effective and needed in the design of classroom instruction to teach mathematics effectively. It has added new insight, from instructional design perspective, into the effectiveness of CRA instructional approach and has made the research evidence more vigorous. The study, again, has added new insight, from the Ghanaian perspective, to the literature on the relevance of instructional design, as a core, for promoting better learning of mathematics. Particularly, the study has stimulated (mathematics) education researchers (in Ghana) and provided them directions to conduct more research on CRA and other instructional strategies based on models and principles of instructional design to contribute to effective teaching of mathematics. The implications of the present study rings to the hearing of governments and educational policy makers that they should stop spending the little money that they have on acquiring technological tools and spend the money on training and motivating teachers to acquire the conceptual tools in effective instructional design and practice.

\section{Acknowledgement}

The authors would like to thank VLIR-UOS as (co)sponsor of the development of this scientific article. Furthermore, they also wish to express their deep appreciation to the Professors, Research Staff, Ph.D students, and Secretariat of the Center for Psychology and Instructional Technology, Faculty of Psychology and Educational Sciences and the Staff of International 
Office, KULeuven, Belgium for their relentless and vigorous support to the first author of this article during his short research stay in Belgium fully sponsored by VLIR-UOS. Finally, the authors wish to thank the Management of University of Education, Winneba, Ghana for their support and cooperation.

\section{References}

Anamuah-Mensah, J., \& Mmereku, D.K. (2005). Ghanaian JSS2 students' abysmal mathematics achievement in TIMSS 2003: A consequence of the basic school mathematics curriculum. Mathematics Connection, 5, 1-13.

Appiah, J. K. (2010). The significance of international comparison of student achievement. West Africa Exams Council. Retrieved 30 January, 2014 from. http://www.1aea.info/documents/paper 30e42a204.pdf

Archer, A. L., \& Hughes, C. A. (2011). From explicit instruction: Effective and efficient teaching. New York: The Guildford Press

Asabere-Ameyaw, A., \& Mmereku, D. K. (2009).Comparative analysis of performance of eight graders from six African Countries. Mathematics Connection, 8(2), 17-26

Baffoe, E., \& Mmereku, D. K. (2010). The van hiele levels of understanding of students entering senior high school in Ghana. African Journal of Educational Studies in Mathematics and Science, 8, 51-61

Butler, F. M., Miller, P. S., Crehan, K., Babbit, B., \& Pierce, T. (2003). Fraction instruction for students with mathematics disabilities: Comparing two teaching sequences. Learning disability Research and Practice 18(2), 99-111

Campbell, D. T., \& Stanley, J. C. (1963). Experimental design for research on teaching. In N. L. Gage (Ed.), Handbook of research and teaching (pp.171-246). Chicago: RandMcNally

Cass, M., Cates, D., Smith, M., \& Jackson, C. (2003). Effect of manipulative instruction on solving area and perimeter problems by students with learning disabilities. Learning Disabilities Research and Practice, 18, 112-120

Delvin, K. (2000). Finding your inner mathematician. The Chronicle of Higher Education, 46, B.

Elen, J. (1995). Blocks on the road to instructional design prescriptions: A methodology for ID research exemplified. Leuven: Leuven University Press

Fredia-Kwarteng, T. (2005). Ghana flunks at mathematics and science. Analysis (1) and (2) 
Gagne, R. M. (1985). The conditions of learning (4 ${ }^{\text {th }}$ ed.). New York: Holt, Rinehart, \& Winston

Gagne, R. M., \& Briggs, L. J. (1979). Principles of instructional design (2 ${ }^{\text {nd }}$ ed.). New York: Holt, Rinehalt, \& Winston

Krathwohl, D. R. (1993). Methods of educational and social science research: An integrated approach. White Plains, NY: Longmans

Kroesbergen, E. H., \& Van Luit J. E. H. (2003). Mathematics interventions for children with special educational needs. Remedial and Special Education, 24, 97-114

Leshin, C.B., Pollock, J., \&Reigeluth, C. M. (1992). Instructional design strategies and tactics. Englewood Cliffs, NJ: Educational Technology Publications

Little, M. (2009). Teaching mathematics : Issues and solutions. Teaching Exceptional Children Plus 6 (1), 1-15

Miller, S. P., Butler, F.M., \& Lee, K. (1998). Validated practices for teaching mathematics to students with learning disabilities: A review of literature. Focus on Exceptional Children, 3(1), 1-24

Ministry of Education. (2007) Republic of Ghana junior high school mathematicssyllabus.Accra: Curriculum Research and Development Division

National Council of Teachers of Mathematics. (1989). Curriculum and Evaluation standards for school Mathematics. National Council of Teachers of Mathematics (1989) Professional Standards for Teaching Mathematics. Reston, VA: NCTM

National Mathematics Advisory Panel (2008). The final report of the national Mathematics Advisory Panel. U.S Department of Education. Retrieved February 1, 2014 from http://www.ed.gov/about/bdscomm/list/mathpanel/repot.pdf

Nilson, L. G. (2000). Remembering actions and words. In E. Tulving,\& F. I. M. Craik (Eds.). The Oxford Handbook of Memory (pp.137-148). New York: Oxford University Press

Owu-Ewie, C. (2012). Language performance and mathematics/science performance: A correlational case study of JHS students in Secondi/Takoradi in Ahanta Districts. The Buckingham Journal of Language and Linguistics, 8, 83-99

Peterson, S. K., Mercer, C.D, \& O’ Shea, L, (1988). Teaching learning disabled students place value using the concrete to abstract sequence. Learning Disabilities Research,4, 5256.

Rosenshine, B. (1987). Explicit teaching and teacher training. Journal of Teacher Education, $38,34-36$ 
Sarfo, F. K., \& Elen, J. (2007). Developing technical expertise in secondary technical schools: The effect of 4C/ID learning environments. Learning Environment Research, 10(3), 207-221. doi: 10.1007/s10984-007-9031-2

Sarfo, F. K., \& Elen, J. (2008). The moderating effect of instructional conceptions on the effect of powerful learning environments. Instructional Science, 38, 137-153 doi:10.1007/s11251-00-9028-8

Seel, N. M. (1997). Model of instructional design: Introduction and overview. In R. D. Tennyson, F. Schott, N. Seel, and S. Dijsktra (Eds.), Solving instructional design problems, instructional design: International perspective Vol. 1 (pp. 335-360). Mahwah, NJ: Lawrence Erlbaum.

Seng, S. (2000). Teaching and learning primary mathematics in Singapore. Paper presented at the annual International Conference and Exhibition of Association for Childhood Education International at Baltimore, AD, April 17-20, 2000

Smaldino, S. E., Lowther, D. L., \& Russell, J. D. (2008). Instructional technology and media for learning ( $8^{\text {th }}$ ed.). Upper Saddle River, NJ: Pearson Education

Strickland, T. K., \&Maccini, P. (2010). Strategies for teaching algebra to students with learning disabilities: Making Research to practice connections. Intervention in School and Clinic, 46(1), 38-45

Sowell, E. J. (1989). Effects of manipulative materials in mathematics instruction. Journal for Research Mathematics Education, 20, 498-509. Retrieved January 30, 2014 from http://coe.jmu.edu/mathdisiabilities. Htm

Van der Linde, I (2005). Performance scores in international maths and science study: Reflective of South African inequalities. Retrieved February 13, 2014 from http://www.hsrc.ac.za/Media.

West Africa Examination Council (2008). Basic Examination Certificate of Examination, Chief Examiner's Report. Accra: West Africa Examination Council

West Africa Examination Council (2009). Basic Examination Certificate of Examination, Chief Examiner's Report. Accra: West Africa Examination Council

West Africa Examination Council (2010). Basic Examination Certificate of Examination, Chief Examiner's Report. Accra: West Africa Examination Council

West Africa Examination Council (2011). Basic Examination Certificate of Examination, Chief Examiner's Report. Accra: West Africa Examination Council

Witzel, B.S. (2005). Using CRA to teach algebra to students with learning difficulties in inclusive settings. Learning Disabilities: A Contemporary Journal, 3(2), 49-60 
Witzel, B. S., Mercer, C. D., \& Miller, M. D. (2003). Teaching algebra with students with learning difficulties: An investigation of an explicit instruction model. Learning Disabilities Research \& Practice, 18, 121-131

Witzel, B. S., Riccomini, P. J.,\& Schneider, E. (2008). Implementing CRA with secondary students with learning disabilities in mathematics. Intervention in School andClinic, 43(5), 270-276 